\title{
A psychometric evaluation of hierarchical and oblique versions of five variants of the Posttraumatic Growth Inventory
}

\author{
Samantha C. Horswill*, Gabrielle Desgagné, Holly A. Parkerson, R. Nicholas Carleton, \\ Gordon J.G. Asmundson \\ Department of Psychology, University of Regina, Regina, SK, Canada
}

\section{A R T I C L E I N F O}

\section{Keywords:}

PTGI

Confirmatory factor analysis

Assessment

Measurement

Trauma

\begin{abstract}
A B S T R A C T
The Posttraumatic Growth Inventory (PTGI; Tedeschi and Calhoun, 1996) is the most commonly used measure of posttraumatic growth. Although the original five factor structure has extensive psychometric support, evidence exists for alternate PTGI models. The current study assessed the validity of oblique and hierarchical factor structures of five PTGI models. Confirmatory factor analyses were performed among a heterogeneous community sample with a diverse trauma history. The oblique models provided a better fit to the data compared with their respective hierarchical models. Three oblique variants provided good fit to the data on two fit indices and all five oblique variants met the recommended criteria for at least one fit index. The 10-item model demonstrated the lowest Expected Cross-Validation Index (ECVI) values and is a brief and useful measure when examining PTGI total scores; however, current results suggest that consideration of the specific subscales may be more meaningful than total scores. Researchers and clinicians interested in subscale scores should consider using the 18- or 21-item variants due to a higher number of items per factor and, therefore, greater factor stability. Future directions in refining and measuring posttraumatic growth are discussed.
\end{abstract}

\section{Introduction}

Trauma literature has historically centered on the negative psychological sequelae of trauma (Bensimon, 2012; Breslau et al., 1998), resulting in advancements in knowledge, treatment, and prevention strategies for posttraumatic stress disorder (PTSD; American Psychiatric Association, 2013). Over the past two decades, however, a developing evidence base has identified a phenomenon of significant and positive psychological change following trauma, commonly referred to as posttraumatic growth (Tedeschi and Calhoun, 1996). Posttraumatic growth is theorized to be facilitated by engagement in cognitive processing, emotional coping, and disclosure, resulting in beneficial changes in self-perception, external relationships, and philosophy on life (Tedeschi and Calhoun, 2004).

The Posttraumatic Growth Inventory (PTGI; Tedeschi and Calhoun, $1996)$ is the primary tool used to measure posttraumatic growth. The PTGI was developed from a pool of 34 items, generated and validated with a sample of trauma-exposed undergraduate students. Principal components analyses have supported five factors, each representing a different domain in which positive growth occurs following trauma: relating to others; new possibilities; personal strength; spiritual change; and appreciation of life (Tedeschi and Calhoun, 1996). The final 21-item measure displayed excellent internal consistency $(a=.90)$ and test-retest reliability $\left(r_{\mathrm{ii}}=.71\right)$. The PTGI has since been utilized in diverse samples, including prisoners of war (Solomon and Dekel, 2007), military veterans (Maguen et al., 2006), cancer patients (Rajandram et al., 2011), pediatric patients (Picoraro et al., 2014), and university students (Taku et al., 2007). The original five factor structure has been replicated in a number of English-language studies (e.g., Brunet et al., 2010; Palmer et al., 2012; Taku et al., 2008) and language translations including Dutch (Jaarsma et al., 2006), German (Mack et al., 2015; Maercker and Langner, 2001), Italian (Prati and Pietrantoni, 2014), Japanese (Taku et al., 2007), and Portuguese (Lamela et al., 2014; Teixeira and Pereira, 2013).

Despite strong evidence for the original five factor 21-item model, several studies have provided psychometric support for alternative PTGI models. Several one and three factor structures were tested by Taku et al. (2008) following statistical evidence of high intercorrelations between factors (e.g., Joseph and Linley, 2004; Sheikh and Marotta, 2005) and internal consistency for the whole measure (e.g., Sears et al., 2003; Sheikh and Marotta, 2005), suggesting posttraumatic growth may either be unidimensional rather than multidimensional or have fewer than five factors (Taku et al., 2008). The psychometric analysis (Taku et al., 2008) suggested the one and three

\footnotetext{
* Corresponding author.

E-mail address: Samantha.Horswill@gmail.com (S.C. Horswill).
} 
factor variants were inferior to the original five factor PTGI. In terms of dimensionality, both oblique and hierarchical factor analyses of the five factor 21-item PTGI had acceptable fit, though the oblique structure was a better fit (Taku et al., 2008). Another alternative oblique model emerged from an investigation assessing the fit of the PTGI factor structure in an ethnically diverse sample of college students; specifically, removal of poorly fitting items resulted in 18 items representing the original five factors (Hooper et al., 2009). Model fit for the revised item set has not been tested with a hierarchical structure. Shortly thereafter, another shortened version of the PTGI was developed through confirmatory factor analysis of 1351 adults across 16 studies (Cann et al., 2010). The resulting 10-item Short Form (PTGI-SF) was comprised of the two highest-loading items in each of the five factors. Oblique and hierarchical models of the PTGI-SF demonstrated good fit, with slightly superior fit for the oblique model (Cann et al., 2010). The PTGI-SF was subsequently validated in a sample of deployed National Guard soldiers (Kaler et al., 2011), supporting its factor structure, reliability, and construct validity.

Amidst the development of the 18- and 10-item PTGI variants came speculation that the posttraumatic growth construct may also encompass increases in compassion after trauma (Morris et al., 2012, 2013). Qualitative research with cancer survivors identified a theme of compassion in oncological psychology (Morris et al., 2012). The result led the authors to hypothesize that the addition of compassion-related items may allow the PTGI to better encompass the construct of posttraumatic growth (Morris et al., 2013). With the assistance of Calhoun (one of the original authors of the PTGI), Morris et al. (2013) developed four additional compassion items for inclusion in the measure. Principal components analysis of the 26 items revealed eight cross-loaded items from the original scale, which were discarded. The remaining 18 items produced a seemingly robust six factor structure that included the original five factors and a sixth factor labeled compassion. The six factor solution demonstrated good fit with both oblique and hierarchical models; however, the authors noted a preference for the oblique model based on its superior fit index values. The six factor model has not been factorially validated on another sample. Additionally, the final compassion factor comprised of four new items and one original item (Morris et al., 2013) has not been reexamined alongside the other original PTGI items (Tedeschi and Calhoun, 1996) in a diverse, non-cancer sample.

To our knowledge, only the original 21-item PTGI (Tedeschi and Calhoun, 1996) has been validated using a community sample with diverse trauma experiences (e.g., Linley et al., 2007; Taku et al., 2008); validation studies with the four alternative variants have been conducted on homogenous samples with specific types of traumas (Kaler et al., 2011; Morris et al., 2013). The current study was designed to assess the goodness-of-fit of oblique and hierarchical models of five PTGI variants-the 21-item five factor model (Tedeschi and Calhoun, 1996); the 10-item five factor model (Cann et al., 2010); the 18-item five factor model (Hooper et al., 2009); the 18-item six factor model (Morris et al., 2013); and an exploratory 25-item six factor model with the original items plus four compassion items (Morris et al., 2013)-in a demographically heterogeneous community sample representing a wide range of index traumas.

\section{Methods}

\subsection{Participants}

Full participant details have been reported in (Asmundson et al., 2016). What follows is a summary of relevant demographic information. Participants comprised an American community sample ( $n=512$; $48 \%$ female; mean age $=48.0, S D=11.8$ ) who reported experiencing a traumatic event. Participants were recruited via Qualtrics Online Survey Software (Provo, UT) as part of a larger study investigating PTSD and other posttraumatic outcomes. Participants were specifically recruited by Qualtrics via a screening question asking whether they had experienced a traumatic event, and were eligible to continue participation if they were 18 years of age or older and endorsed exposure to one or more traumatic events. Participants were primarily White $(80.7 \%)$; married/cohabitating (56.6\%) or single (23.6\%); and employed full time $(41.4 \%)$ or part time $(13.3 \%)$. In terms of index trauma, participants primarily endorsed illness/injury (15.6\%), transportation accident (14.6\%), sudden accidental death (8.8\%), natural disaster (8.6\%), sexual assault (7.0\%), and physical assault (7.0\%). Index traumas occurred an average of 14.4 years $(S D=13.5$; range=less than a year to 55 years) prior to survey completion.

\subsection{Measures}

The PTGI (Tedeschi and Calhoun, 1996) is a 21-item measure assessing the five factors originally theorized to comprise posttraumatic growth (i.e., relating to others, new possibilities, personal strength, spiritual change, and appreciation of life). Respondents were instructed to fill out the questionnaire in response to the trauma they previously rated as their index (i.e., most severe) traumatic experience. Each factor contains between two (i.e., spiritual change) and seven (i.e., relating to others) items. Items such as "I know better that I can handle difficulties" are rated on a 0 ( $I$ did not experience this change as a result of my crisis) to 5 ( $I$ experienced this change to a very great degree as a result of my crisis) scale. Low summed scores indicate low posttraumatic growth and high summed scores indicate high posttraumatic growth. In addition to the original 21 items, the present research included the four items developed for the compassion factor of the Morris et al. (2013) PTGI variant. Items such as "If I see someone who needs help I have a stronger desire to help them" are rated on the same 0-5 scale as above. Item 15 of the original PTGI (e.g., "I have more compassion for others") is included in the compassion factor in the relevant models. The items representing each factor in each PTGI variant under consideration are presented in Table 1.

\subsection{Data analytic plan}

Visual inspection of score distribution plots (Field, 2013) suggested a non-normal distribution of the data. Therefore, bootstrapped analyses with 1000 samples were used to provide robust probability values and confidence intervals. Cronbach's alpha was calculated in order to assess the internal consistency of the total and subscale scores of the PTGI and model variants. Confirmatory factor analyses (CFAs) were conducted to assess the goodness-of-fit of the five PTGI variants as oblique and hierarchical models. The models tested included the 21item five factor model (Tedeschi and Calhoun, 1996), the 10-item five factor model (Cann et al., 2010), the 18-item five factor model (Hooper et al., 2009), the 18-item six factor model (Morris et al., 2013), and a 25-item six factor model with the original PTGI items (Tedeschi and Calhoun, 1996) plus compassion items (Morris et al., 2013). The items included in each of the PTGI models are presented in Tables 1 and 2. The CFA analyses were performed using AMOS (version 22) with maximum likelihood estimation and oblique rotation.

Model fit was evaluated using multiple fit indices as recommended by $\mathrm{Hu}$ and Bentler (1999): chi square/degrees of freedom ratio $\left(\chi^{2} / \mathrm{df}\right.$; values should be <2.0); comparative fit index (CFI; values should approach or be >.95); root mean square error of approximation (RMSEA; values should approach or be <.06); standardized root mean square residual (SRMR; values should approach or be <.08); and the Expected Cross-Validation Index (ECVI; lower values indicate better fit). More value should be placed on the last four fit indices because chi-square values are sensitive to large sample sizes ( $\mathrm{Hu}$ and Bentler, 1999). 
Table 1

Unstandardized Loadings (Standard Errors) and Standardized Loadings of items in the oblique Posttraumatic Growth Inventory variants.

\begin{tabular}{|c|c|c|c|c|c|c|c|c|c|c|c|c|}
\hline \multirow[b]{2}{*}{ Items } & \multicolumn{2}{|l|}{ Factor I } & \multicolumn{2}{|c|}{ Factor II } & \multicolumn{2}{|c|}{ Factor III } & \multicolumn{2}{|c|}{ Factor IV } & \multicolumn{2}{|c|}{ Factor V } & \multicolumn{2}{|c|}{ Factor VI } \\
\hline & $\mathrm{U}(\mathrm{SE})$ & $\mathrm{S}$ & $\mathrm{U}(\mathrm{SE})$ & $\mathrm{S}$ & $\mathrm{U}(\mathrm{SE})$ & $\mathrm{S}$ & $\mathrm{U}(\mathrm{SE})$ & $\mathrm{S}$ & $\mathrm{U}(\mathrm{SE})$ & $\mathrm{S}$ & $\mathrm{U}(\mathrm{SE})$ & $\mathrm{S}$ \\
\hline
\end{tabular}

21item, five factor ${ }^{\mathrm{a}}$

$\begin{array}{lllll}\text { five factor }^{\mathrm{a}} & & & & \\ 6 & 1.00(-) & .80 & & \\ 8 & 1.04(.05) & .86 & & \\ 9 & 1.02(.05) & .83 & & \\ 15 & .94(.05) & .75 & & \\ 16 & 1.02(.05) & .82 & & \\ 20 & 1.04(.5) & .85 & & .78 \\ 21 & 1.05(.5) & .88 & & .82 \\ 3 & & & 1.00(-) & .11(.05) \\ 7 & & & 1.11 .05) & .89 \\ 11 & & & .97(.05) & .75 \\ 14 & & & 1.12(.05) & .85 \\ 17 & & & \end{array}$

$\begin{array}{ll}1.00(-) & .79 \\ 1.01(.05) & .85 \\ 1.02(.05) & .84 \\ .97(.05) & .76\end{array}$

$\begin{array}{ll}1.00(-) & .95 \\ .92(.04) & .83\end{array}$

$\begin{array}{ll}1.00(-) & .69 \\ 1.22(.07) & .83 \\ 1.4(.08) & .90\end{array}$

10-item, five factor ${ }^{\mathrm{b}}$

$\begin{array}{lll}8 & 1.04(.05) & .87 \\ 20 & 1.00(-) & .83 \\ 11 & & \\ 7 & & \\ 10 & & \\ 19 & & \\ 5 & & \\ 18 & & \\ 1 & & \\ 2 & & \end{array}$

$\begin{array}{ll}1.00(-) & .88 \\ .94(.04) & .80\end{array}$

$\begin{array}{ll}1.00(.05) & .88 \\ 1.00(-) & .82\end{array}$

$1.00(-) \quad .95$

$.91(.04) \quad .83$

$\begin{array}{ll}.90(.05) & .79 \\ 1.00(-) & .86\end{array}$

18-item, five factor

$\begin{array}{lll}6 & 1.00(-) & .81 \\ 8 & 1.03(.04) & .86 \\ 15 & .89(.05) & .73 \\ 20 & 1.03(.04) & .86 \\ 21 & 1.04(.04) & .88 \\ 9 & 1.00(.05) & .83 \\ 3 & & \end{array}$

$\begin{array}{ll}1.00(-) & .78 \\ 1.12(.05) & .82 \\ 1.17(.05) & .89 \\ .98(.05) & .75 \\ 1.11(.05) & .85\end{array}$

$\begin{array}{ll}1.00(-) & .79 \\ 1.01(.05) & .83 \\ .92(-.05) & .72\end{array}$

$1.00(-) \quad .95$

$.96(.04) \quad .83$

$.00(-) \quad .81$

$1.22(.05) \quad .94$

18-item, six factor ${ }^{\mathrm{d}}$

$\begin{array}{lll}6 & 1.00(-) & .82 \\ 21 & 1.05(.04) & .90 \\ 20 & 1.06(.04) & .89 \\ 3 & & \\ 7 & & \\ 14 & \\ 11 & \\ 12 & \\ 10 & \\ 18 & \\ 5 & \\ 1 & \\ 2 & \\ \mathrm{C} 1 & \\ \mathrm{C} 2 & \\ 15 & \end{array}$

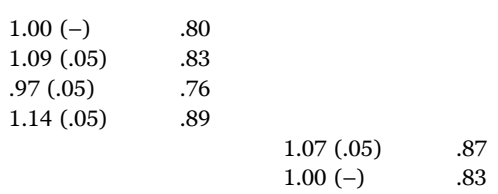

$\begin{array}{ll}.93(.04) & .84 \\ 1.00(-) & .94\end{array}$
$.1 .00(-)$
$1.06(.06)$
.81

$\begin{array}{lc}.1 .00(-) & .89 \\ .88(.04) & .74 \\ .95(.04) & .81 \\ \text { continued on next page) }\end{array}$ 
Table 1 (continued)

\begin{tabular}{|c|c|c|c|c|c|c|c|c|c|c|c|c|}
\hline \multirow[b]{2}{*}{ Items } & \multicolumn{2}{|l|}{ Factor I } & \multicolumn{2}{|l|}{ Factor II } & \multicolumn{2}{|l|}{ Factor III } & \multicolumn{2}{|l|}{ Factor IV } & \multicolumn{2}{|l|}{ Factor V } & \multicolumn{2}{|l|}{ Factor VI } \\
\hline & $\mathrm{U}(\mathrm{SE})$ & $\mathrm{S}$ & $\mathrm{U}(\mathrm{SE})$ & $\mathrm{S}$ & $\mathrm{U}(\mathrm{SE})$ & $\mathrm{S}$ & $\mathrm{U}(\mathrm{SE})$ & $\mathrm{S}$ & $\mathrm{U}(\mathrm{SE})$ & $\mathrm{S}$ & $\mathrm{U}(\mathrm{SE})$ & $\mathrm{S}$ \\
\hline $\mathrm{C} 3$ & & & & & & & & & & & $1.03(.04)$ & .89 \\
\hline $\mathrm{C} 4$ & & & & & & & & & & & $1.02(.04)$ & .89 \\
\hline \multicolumn{13}{|c|}{ 25-item, six factor ${ }^{\mathrm{e}}$} \\
\hline 6 & $1.00(-)$ & .80 & & & & & & & & & & \\
\hline 8 & $1.05(.05)$ & .87 & & & & & & & & & & \\
\hline 9 & $1.02(.05)$ & .83 & & & & & & & & & & \\
\hline 16 & $1.01(.05)$ & .81 & & & & & & & & & & \\
\hline 20 & $1.04(.05)$ & .86 & & & & & & & & & & \\
\hline 21 & $1.05(.04)$ & .88 & & & & & & & & & & \\
\hline 3 & & & $1.00(-)$ & .78 & & & & & & & & \\
\hline 7 & & & $1.11(.05)$ & .82 & & & & & & & & \\
\hline 11 & & & $1.17(.05)$ & .89 & & & & & & & & \\
\hline 14 & & & $.97(.05)$ & .74 & & & & & & & & \\
\hline 17 & & & $1.13(.05)$ & .85 & & & & & & & & \\
\hline 4 & & & & & $1.00(-)$ & .79 & & & & & & \\
\hline 10 & & & & & $1.01(.05)$ & .85 & & & & & & \\
\hline 12 & & & & & $1.02(.05)$ & .84 & & & & & & \\
\hline 19 & & & & & $.98(.05)$ & .77 & & & & & & \\
\hline 5 & & & & & & & $1.00(-)$ & .94 & & & & \\
\hline 18 & & & & & & & $.94(.04)$ & .84 & & & & \\
\hline 1 & & & & & & & & & $1.00(-)$ & .70 & & \\
\hline 2 & & & & & & & & & $1.21(.07)$ & .83 & & \\
\hline 13 & & & & & & & & & $1.4(.07)$ & .90 & & \\
\hline $\mathrm{C} 1$ & & & & & & & & & & & $1.00(-)$ & .89 \\
\hline $\mathrm{C} 2$ & & & & & & & & & & & $.88(.04)$ & .74 \\
\hline 15 & & & & & & & & & & & $.96(.04)$ & .82 \\
\hline $\mathrm{C} 3$ & & & & & & & & & & & $1.03(.04)$ & .89 \\
\hline $\mathrm{C} 4$ & & & & & & & & & & & $1.02(.04)$ & .89 \\
\hline
\end{tabular}

Note. U, unstandardized; SE, standard error; S, standardized. The authors for each of the models are denoted as follows:

a Tedeschi and Calhoun (1996).

b Cann et al. (2010).

c Hooper et al. (2009).

d Morris et al. (2013).

e Original PTGI items plus compassion factor.

\section{Results}

All PTGI variants demonstrated strong internal consistency for total scale scores, ranging from .93 to 97 . Internal consistency subscale scores were also generally strong, ranging from .81 to .94 , with the exception of Factor $1(\alpha=.70)$ of the PTGI-SF (Cann et al., 2010). Full internal consistency results are presented in Table 3.

CFA results indicated that all oblique models provided good fit to the data based on SRMR indices. Two oblique models, the 10-item five factor and 18-item six factor, demonstrated a CFI value of .95 or higher. Likewise, the CFI value for the oblique 18-item five factor model was .94. The 21-item five factor and 25-item five factor oblique models both had slightly lower CFI values of .91. A guideline provided by Hu and Bentler (1999) states that CFI values should approach or be greater than .95 . The first three oblique models meet this recommendation. The $\chi^{2} / \mathrm{df}$ values for all oblique models were above the recommended value of 2.0, which is to be expected given the large sample size (Kenny and McCoach, 2003). RMSEA values for all oblique models were also above the recommended value of .06. The ECVI, a comparative fit index, was lowest for the 10-item five factor oblique model of the PTGI-SF (Cann et al., 2010) and followed, in rank order, by the 18-item five factor model (Hooper et al., 2009), the 18-item six factor model (Morris et al., 2013), the 21-item five factor model (Tedeschi and Calhoun, 1996), and the 25-item six factor oblique model. Fit indices for the models are presented in Table 4. The standardized factor loadings for all oblique models were high, ranging from .66 to .95 . Factor loadings for the items from each oblique model are displayed in Table 1.

The fit of each model variant worsened when tested using hierarchical models. Specifically, the CFI values did not meet the recom- mended guidelines for any of the models (CFI ranged from .79 to .85; $\mathrm{Hu}$ and Bentler, 1999). The RMSEA and ECVI values of each hierarchical model were significantly lower than the respective oblique models, as indicated by non-overlapping confidence intervals. Nevertheless, the SRMR values were within the recommended value of .08 for all models (SRMR values ranged from .06 to .07). The standardized factor loadings for all hierarchical models were high, ranging from .69 to .95 . Factor loadings for the items from each model are displayed in Table 2.

\section{Discussion}

The current study was designed to assess the goodness-of-fit of five different PTGI models in a community sample with a heterogeneous trauma exposure history using oblique and hierarchical models. With respect to the oblique PTGI variants, all models met the recommended SRMR value provided by $\mathrm{Hu}$ and Bentler (1999). The 10-item five factor, 18-item six factor, and the 18-item five factor models demonstrated good fit on the CFI index. The remaining two oblique models (original 21-item five factor and exploratory 25-item five factor) did not meet with CFI recommendations from $\mathrm{Hu}$ and Bentler (1999). The RMSEA and $\chi^{2} / \mathrm{df}$ values were above recommended values for all oblique models; however, the $\chi^{2} / \mathrm{df}$ results were expected given the large sample size (Hu and Bentler, 1999). The ECVI values differed across the oblique PTGI models with values ranging from .45 to 2.94. The ECVI is used to compare multiple models whereby the model with the lowest ECVI value has the highest probability of replication (Byrne, 2010). The oblique PTGI-SF model demonstrated the lowest ECVI value (.45) with confidence intervals that did not overlap with the confidence intervals of the other models. The oblique models with the 
Table 2

Unstandardized Loadings (Standard Errors) and Standardized Loadings of items in the hierarchical Posttraumatic Growth Inventory variants.

\begin{tabular}{|c|c|c|c|c|c|c|c|c|c|c|c|c|}
\hline \multirow[b]{2}{*}{ Items } & \multicolumn{2}{|l|}{ Factor I } & \multicolumn{2}{|c|}{ Factor II } & \multicolumn{2}{|c|}{ Factor III } & \multicolumn{2}{|c|}{ Factor IV } & \multicolumn{2}{|c|}{ Factor V } & \multicolumn{2}{|c|}{ Factor VI } \\
\hline & $\mathrm{U}(\mathrm{SE})$ & $\mathrm{S}$ & $\mathrm{U}(\mathrm{SE})$ & S & $\mathrm{U}(\mathrm{SE})$ & S & $\mathrm{U}(\mathrm{SE})$ & S & $\mathrm{U}(\mathrm{SE})$ & $S$ & $\mathrm{U}(\mathrm{SE})$ & $\mathrm{S}$ \\
\hline
\end{tabular}

21item, five factor ${ }^{\mathrm{a}}$

$\begin{array}{lllll}6 & 1.00(-) & .73 & & \\ 8 & 1.07(.06) & .81 & & \\ 9 & 1.06(.06) & .79 & & \\ 15 & 1.03(.06) & .76 & & \\ 16 & 1.11(.06) & .82 & & \\ 20 & 1.04(.6) & .78 & & \\ 21 & 1.04(.6) & .80 & & .74 \\ 3 & & & 1.00(-) & .78 \\ 7 & & & 1.11(.06) & .85 \\ 11 & & & 1.18(.06) & .89 \\ 14 & & & .99(.06) & .71 \\ 17 & & & 1.18(.06) & .84 \\ 4 & & & & \end{array}$

$\begin{array}{ll}1.00(-) & .74 \\ .98(.05) & .78 \\ 1.02(.05) & .79 \\ .97(.06) & .71\end{array}$

$\begin{array}{ll}1.00(-) & .76 \\ .95(.06) & .68\end{array}$

$\begin{array}{ll}1.00(-) & .66 \\ 1.13(.07) & .74 \\ 1.4(.08) & .84\end{array}$

10-item, five factor ${ }^{\mathrm{b}}$

$\begin{array}{lll}8 & 1.03(.06) & .77 \\ 20 & 1.00(-) & .75 \\ 11 & & \\ 7 & & \\ 10 & & \\ 19 & & \\ 5 & & \\ 18 & & \\ 1 & & \\ 2 & & \end{array}$

$\begin{array}{ll}1.00(-) & .82 \\ .95(.05) & .76\end{array}$

$\begin{array}{ll}.97(.05) & .78 \\ 1.00(-) & .74\end{array}$

$\begin{array}{ll}1.00(-) & .79 \\ .94(.06) & .71\end{array}$

$\begin{array}{ll}.90(.06) & .69 \\ 1.00(-) & .75\end{array}$

18-item, five factor

$\begin{array}{lll}6 & 1.00(-) & .74 \\ 8 & 1.05(.06) & .81 \\ 15 & 1.01(.06) & .75 \\ 20 & 1.03(.06) & .79 \\ 21 & 1.03(.05) & .80 \\ 9 & 1.05(.06) & .80 \\ 3 & & \\ 7 & & \\ 11 & & \\ 14 & & \\ 17 & & \\ 4 & & \\ 12 & & \\ 19 & & \\ 5 & & \\ 18 & & \\ 2 & & \\ 13 & & \end{array}$

$\begin{array}{ll}1.00(-) & .74 \\ 1.12(.06) & .78 \\ 1.18(.06) & .84 \\ 1.00(.06) & .72 \\ 1.17(.06) & .84\end{array}$

$$
\begin{array}{ll}
1.00(-) & .75 \\
1.01(.05) & .79 \\
.95(.06) & .70
\end{array}
$$$$
\begin{array}{ll}
1.00(-) & .76 \\
.94(.06) & .68
\end{array}
$$$$
1.00(-) \quad .73
$$$$
1.20(.06) \quad .83
$$

18-item, six factor ${ }^{\mathrm{d}}$

$\begin{array}{lll}6 & 1.00(-) & .72 \\ 21 & 1.05(.06) & .79 \\ 20 & 1.05(.06) & .78 \\ 3 & & \\ 7 & & \\ 14 & \\ 11 & \\ 12 & \\ 10 & \\ 18 & \\ 5 & \\ 1 & \\ 2 & \\ \mathrm{C} 1 & \\ \mathrm{C} 2 & \\ 15 & \end{array}$

$\begin{array}{ll}1.00(-) & .72 \\ 1.11(.07) & .76 \\ .97(.06) & .69 \\ 1.17(.06) & .82\end{array}$

$$
\begin{array}{ll}
.96(.06) & .70 \\
1.00(-) & .77
\end{array}
$$

$\begin{array}{ll}1.00(-) & .67 \\ 1.10(.07) & .72\end{array}$

$1.00(-) \quad .79$ $.99(.05) \quad .74$

1.05 (.05) $\quad .80$ (continued on next page) 
Table 2 (continued)

\begin{tabular}{|c|c|c|c|c|c|c|c|c|c|c|c|c|}
\hline \multirow[b]{2}{*}{ Items } & \multicolumn{2}{|l|}{ Factor I } & \multicolumn{2}{|l|}{ Factor II } & \multicolumn{2}{|l|}{ Factor III } & \multicolumn{2}{|l|}{ Factor IV } & \multicolumn{2}{|l|}{ Factor V } & \multicolumn{2}{|l|}{ Factor VI } \\
\hline & $\mathrm{U}(\mathrm{SE})$ & S & $\mathrm{U}(\mathrm{SE})$ & $\mathrm{S}$ & $\mathrm{U}(\mathrm{SE})$ & $\mathrm{S}$ & $\mathrm{U}(\mathrm{SE})$ & $\mathrm{S}$ & $\mathrm{U}(\mathrm{SE})$ & $\mathrm{S}$ & $\mathrm{U}(\mathrm{SE})$ & $\mathrm{S}$ \\
\hline $\mathrm{C} 3$ & & & & & & & & & & & $1.03(.05)$ & .79 \\
\hline $\mathrm{C} 4$ & & & & & & & & & & & $1.03(.05)$ & .80 \\
\hline \multicolumn{13}{|c|}{ 25-item, six factor ${ }^{\mathrm{e}}$} \\
\hline 6 & $1.00(-)$ & .73 & & & & & & & & & & \\
\hline 8 & $1.06(.06)$ & .80 & & & & & & & & & & \\
\hline 9 & $1.06(.06)$ & .79 & & & & & & & & & & \\
\hline 16 & $1.13(.06)$ & .82 & & & & & & & & & & \\
\hline 20 & $1.05(.06)$ & .78 & & & & & & & & & & \\
\hline 21 & $1.05(.06)$ & .80 & & & & & & & & & & \\
\hline 3 & & & $1.00(-)$ & .72 & & & & & & & & \\
\hline 7 & & & $1.12(.06)$ & .76 & & & & & & & & \\
\hline 11 & & & $1.19(.06)$ & .83 & & & & & & & & \\
\hline 14 & & & $.98(.06)$ & .70 & & & & & & & & \\
\hline 17 & & & $1.21(.06)$ & .85 & & & & & & & & \\
\hline 4 & & & & & $1.00(-)$ & .73 & & & & & & \\
\hline 10 & & & & & $.98(.06)$ & .77 & & & & & & \\
\hline 12 & & & & & $1.02(.06)$ & .78 & & & & & & \\
\hline 19 & & & & & $1.00(.06)$ & .72 & & & & & & \\
\hline 5 & & & & & & & $1.00(-)$ & .76 & & & & \\
\hline 18 & & & & & & & $.96(.06)$ & .69 & & & & \\
\hline 1 & & & & & & & & & $1.00(-)$ & .67 & & \\
\hline 2 & & & & & & & & & $1.12(.07)$ & .74 & & \\
\hline 13 & & & & & & & & & $1.34(.08)$ & .83 & & \\
\hline $\mathrm{C} 1$ & & & & & & & & & & & $1.00(-)$ & .77 \\
\hline $\mathrm{C} 2$ & & & & & & & & & & & $.99(.06)$ & .71 \\
\hline 15 & & & & & & & & & & & $1.07(.06)$ & .79 \\
\hline $\mathrm{C} 3$ & & & & & & & & & & & $1.03(.06)$ & .77 \\
\hline $\mathrm{C} 4$ & & & & & & & & & & & $1.03(.05)$ & .77 \\
\hline
\end{tabular}

Note. U, unstandardized; SE, standard error; S, standardized. The authors for each of the models are denoted as follows:

a Tedeschi and Calhoun (1996).

b Cann et al. (2010).

c Hooper et al. (2009).

d Morris et al. (2013).

e Original PTGI items plus compassion factor.

next lowest ECVI values were the 18-item six factor (1.20) and the 18item five factor (1.39) models, which both had confidence intervals that did not overlap with the higher item models (21-item five factor, 25item six factor). Most indices favour simpler models (Hoyle, 2012) and, although the ECVI may be particularly robust to such bias (Hoyle, 2012), statistical comparisons across non-nested models can still be unreliable (for discussion, see Merkle et al., 2015). As such, replication of the current finding is necessary.

The fit of the five PTGI model variants was also assessed using hierarchical factor structures. Across models, only the SRMR fit index demonstrated values that were entirely consistent with recommendations. The remaining fit indices indicated that the hierarchical models did not fit the data as well as the oblique models for the same variants. Specifically, the CFI values did not meet recommended guidelines for any of the hierarchical models (Hu and Bentler, 1999). The RMSEA and ECVI values of each hierarchical model were significantly lower than the respective oblique models.

In sum, as previously supported by comparisons of hierarchical and oblique models (Cann et al., 2010; Morris et al., 2013; Taku et al., 2008), the oblique models were a better fit to the data than the hierarchical models across all of the PTGI variants. The PTGI-SF (Cann et al., 2010) oblique model may be most replicable and has the additional benefit of brevity. The majority of extant research utilizes PTGI total scores for statistical analyses (Helgeson et al., 2006); however, mounting evidence suggests that consideration of the specific subscales may be more meaningful for interpreting PTGI than a total score. As such, a longer measure, like the 18-item six factor or 18-item five factor, could be important for researchers interested in utilizing the PTGI subscale scores. Likewise, a longer PTGI measure may be most appropriate for identifying clinical posttraumatic growth targets and

Table 3

Cronbach's alpha values for total and subscale scores of all variants.

\begin{tabular}{|c|c|c|c|c|c|c|c|}
\hline Model & Total & Factor I & Factor II & Factor III & Factor IV & Factor V & Factor VI \\
\hline 21-item, five factor ${ }^{a}$ & .97 & .94 & .91 & .88 & .88 & .85 & - \\
\hline 10-item, five factor ${ }^{b}$ & .93 & .70 & .83 & .84 & .88 & .81 & - \\
\hline 18-item, five factor ${ }^{c}$ & .96 & .93 & .91 & .82 & .88 & .86 & - \\
\hline 18-item, six factor ${ }^{\mathrm{d}}$ & .96 & .90 & .89 & .84 & .88 & .81 & .92 \\
\hline 25-item, six factor ${ }^{\mathrm{e}}$ & .97 & .93 & .91 & .88 & .88 & .85 & .92 \\
\hline
\end{tabular}

Note. The authors for each of the models are denoted as follows:

a Tedeschi and Calhoun (1996).

b Cann et al. (2010).

${ }^{\mathrm{c}}$ Hooper et al. (2009).

d Morris et al. (2013).

e Original PTGI items plus compassion factor. 
Table 4

Results of confirmatory factor analyses of oblique and hierarchical Posttraumatic Growth Inventory variants.

\begin{tabular}{|c|c|c|c|c|c|c|c|c|}
\hline Model & & $\chi^{2} / \mathrm{df}$ & CFI & RMSEA & RMSEA CI & SRMR & ECVI & ECVI CI \\
\hline \multirow[t]{2}{*}{ 21-item, five factor ${ }^{a}$} & Oblique & 5.91 & .91 & .10 & $.09-.10$ & .04 & 2.28 & $2.08-2.48$ \\
\hline & Hierarchical & 10.13 & .82 & .13 & $.13-.14$ & .06 & 3.91 & $3.65-4.19$ \\
\hline \multirow[t]{2}{*}{ 10-item, five factor ${ }^{\mathrm{b}}$} & Oblique & 6.85 & .96 & .11 & $.09-.12$ & .03 & .45 & $.38-.54$ \\
\hline & Hierarchical & 16.63 & .85 & .18 & $.16-.19$ & .06 & 1.22 & $1.07-1.38$ \\
\hline \multirow[t]{2}{*}{ 18-item, five factor ${ }^{c}$} & Oblique & 4.94 & .94 & .09 & $.08-.10$ & .04 & 1.39 & $1.24-1.55$ \\
\hline & Hierarchical & 10.48 & .84 & .14 & $.13-.14$ & .06 & 2.91 & $2.68-3.16$ \\
\hline \multirow[t]{2}{*}{ 18-item, six factor ${ }^{\mathrm{d}}$} & Oblique & 4.28 & .95 & .08 & $.07-.09$ & .04 & 1.20 & $1.07-1.35$ \\
\hline & Hierarchical & 13.07 & .79 & .15 & $.15-.16$ & .07 & 3.60 & $3.34-3.87$ \\
\hline \multirow[t]{2}{*}{ 25-item, six factor ${ }^{\mathrm{e}}$} & Oblique & 5.07 & .91 & .09 & $.08-.09$ & .05 & 2.84 & $2.62-3.06$ \\
\hline & Hierarchical & 9.92 & .80 & .13 & $.13-.14$ & .06 & 5.54 & $5.22-5.87$ \\
\hline
\end{tabular}

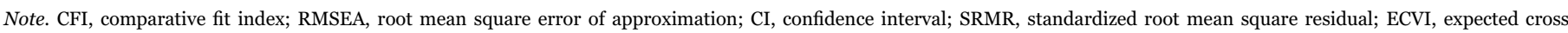
validation index; $\alpha$, Cronbach's alpha. The authors for each of the models are denoted as follows: $j$, original PTGI items plus compassion factor.

a Tedeschi and Calhoun (1996).

b Cann et al. (2010).

c Hooper et al. (2009).

d Morris et al. (2013).

e Original PTGI items plus compassion factor;

measuring clinical outcomes.

Contrary to previous research, the original 21-item five factor PTGI demonstrated good fit according to only one fit index. The original PTGI has demonstrated a robust factor structure in several diverse trauma samples (e.g., Linley et al., 2007; Taku et al., 2008). The robustness of the original PTGI in previous research, coupled with acceptable fit on one fit index in the present study, suggests the original PTGI cannot be dismissed as a poorly fitting model in diverse trauma samples; nevertheless, the unacceptable fit of the original PTGI in other samples has been the impetus for modifications to the PTGI (for review, see Taku et al., 2008). Continued exploration appears warranted to determine whether the inconsistent factor structure results are representative of problems associated with the measure or with contemporary conceptualizations of posttraumatic growth. Finally, the 25-item PTGI was included in the current analyses as an exploratory variant comprised of the original PTGI items (Tedeschi and Calhoun, 1996) and the compassion subscale (Morris et al., 2013). Only one fit index met the recommended value for this variant and, as such, we do not recommend future use of this exploratory 25-item variant. For clinicians and researchers who are interested in utilizing a PTGI variant that includes compassion, the 18-item six factor model is an option which meets criteria for good fit on several indices.

The research on the proposed compassion factor is emerging as a new area of inquiry in the posttraumatic growth literature and has not undergone external psychometric analysis since its initial development (Morris et al., 2012, 2013). The compassion items were developed from a sound theoretical rationale derived from qualitative research (as reviewed in the Morris et al., 2012, 2013). However, the 18-item compassion variant has rarely been used in research, with only two uses so far (Dyer et al., 2016a, 2016b). The limited use of the compassion items may have been due to exclusive use with illnessrelated trauma studies. Researchers may also have refrained from using the compassion items pending external psychometric validation, which the present study provides. Lastly, there may yet be unpublished research with the compassion items, since the few publications that do exist were very recent. Regardless of the reason for slow uptake of the 18-item compassion variant, compassion represents a potentially important dimension of posttraumatic growth and the current psychometric validation supports further research with the 18-item measure.

The high number of PTGI variants available for consideration in the current psychometric evaluation, as well as in Taku et al. (2008) earlier evaluation, serves as evidence that research in the area of posttrau- matic growth is rapidly expanding-a natural outcome of a quickly growing literature being pursued by many researchers (Jayawickreme and Blackie, 2014). As the number of published PTGI variants increase, especially those that introduce new factors (e.g., compassion), confidence that all PTGI measures capture the same elements of the posttraumatic growth construct will likely decrease. Future research designed to inform the conceptual boundaries of posttraumatic growth would likely be beneficial for developing more robust models.

Qualitative investigations may help to clarify the conceptual boundaries of posttraumatic growth. Existing qualitative analysis has provided support for the five-factor structure of PTGI (Taubman-BenAri et al., 2011); however, the study was designed to validate content assumptions and did not comment whether additional themes arose. Atheoretical qualitative analyses of the lived experience of growth and benefit-finding following trauma exposure may provide insight into the number of factors that best represents the posttraumatic growth construct. Similarly, future research should examine whether the posttraumatic growth factors generalize to all trauma types or whether they are specific to trauma type. For example, compassion content appears to be related to posttraumatic growth in samples with healthrelated trauma (e.g., prostate cancer; Morris et al., 2012, 2013), and the 18-item compassion-inclusive PTGI variant demonstrated good fit to our sample of diverse trauma experiences. Qualitative research would shed insight into whether compassion is as salient to individuals who have experienced non-illness traumas. Such qualitative exploration of compassion-related growth may help guide future quantitative analytic investigations.

Likewise, specific quantitative analyses may prove necessary in order to create a common direction in the posttraumatic growth literature. For example, researchers have begun using multiple regression analyses to determine whether core beliefs and ruminative tendencies predict individual responses to specific items using a Japanese translation of the PTGI (Taku and Oshio, 2015). Such work should be replicated across English PTGI variants and other foreign language translations. Additionally, item response theory modeling may clarify whether certain items are underperforming, either globally or in certain samples. The macro-level clarification of posttraumatic growth as a qualitative construct, coupled with the micro-level analysis of item characteristics, is likely to provide a more unified understanding of posttraumatic growth and therein improve measurement of the construct.

There are several limitations to the current investigation that 
provide opportunities for future research. First, the data were obtained through Internet-delivered, anonymous, self-report questionnaires. By their very nature, self-report methods may affect the validity of the results through inaccurate self-reporting caused by recall bias, social desirability bias, or poor recollection. Second, the demographic characteristics may represent a limitation for generalization. Demographics of the present sample were representative of other large-scale investigations of PTSD (e.g., Sledjeski et al., 2008); however, all of the participants resided in the United States, and the sample comprised primarily of individuals that identified as White. Results from the present analyses may only be relevant in a North American context and may not reflect potential cultural differences in how people respond to traumatic events and experience posttraumatic growth (Splevins et al., 2010). Though the present study focused on a review of English variants of the PTGI, an evaluation of psychometric analyses of translated PTGI variants may shed insight into cross-cultural similarities and differences. The diversity of trauma types presented within the current sample was considered a strength of our investigation, as sample heterogeneity may result in greater generalizability to nonspecific samples. Even so, a convenience sample was utilized and representativeness to any given population cannot be assumed. Future research is needed to more specifically assess the factor structure of the PTGI in heterogeneous trauma exposure by geographic region, ethnicity, and other important demographic factors.

Finally, participants were eligible to participate regardless of when the index trauma occurred, resulting in broad individual differences in time since the event $(M=14.4$ years; $S D=13.5)$; that said, negative responses to trauma exposure can persist for decades (e.g., O'Toole et al., 2009; van den Berg et al., 2012) and other publications have reported similar average times since the index trauma (e.g., 14.8 years; Steel et al., 2002). As such, heterogeneous time since index trauma is not considered to be a critical detriment to the present psychometric analysis.

The current investigation assessed the factorial validity of five PTGI model variants using oblique and hierarchical factor structures. The oblique models were superior to the hierarchical models across all of the PTGI variants, which suggests that consideration of the specific subscales may be more meaningful than total scores. In terms of the oblique models, the PTGI-SF (Cann et al., 2010) demonstrated the lowest ECVI value and has the added benefit of brevity; however, a longer measure may be necessary to obtain reliable subscale results, as factors with fewer than three items are notoriously unreliable (O'Rourke and Hatcher, 2013). Researchers and clinicians interested in individual factor scores may therefore want to consider using the 18or 21-item PTGI variants. The body of research designed to measure and predict resilient psychological responses following trauma is rapidly expanding, as is research designed to refine our conceptualization and measurement of posttraumatic growth. Atheoretical qualitative research and item-level analyses may be helpful next steps in identifying whether there is a PTGI variant which most wholly captures the posttraumatic growth construct without sacrificing psychometric robustness.

\section{Acknowledgement}

The authors declare no conflicts of interest. Samantha C. Horswill and Holly A. Parkerson are supported by Canadian Institutes of Health Research Regional Partnerships Program doctoral awards. R.N. Carleton's research is supported by the Canadian Institutes of Health Research through a New Investigator Salary Award (FRN: 13666). Gordon J.G. Asmundson was supported, in part, by the University of Regina President's Chair for Academic Excellence in Adult Mental Health Research.

\section{Appendix A. Supplementary material}

Supplementary data associated with this article can be found in the online version at doi:10.1016/j.psychres.2016.10.027.

\section{References}

American Psychiatric Association, 2013. Diagnostic and Statistical Manual of Mental Disorders 5th ed.. Author, Washington, DC.

Asmundson, G.J.G., LeBouthillier, D.M., Parkerson, H.A., Horswill, S.C., 2016. Traumaexposed community-dwelling women and men respond similarly to the DAR-5 Anger Scale: factor structure invariance and differential item functioning. J. Trauma. Stress 29, 214-220.

Bensimon, M., 2012. Elaboration on the association between trauma, PTSD and posttraumatic growth: the role of trait resilience. Personal. Individ. Differ. 52 (7), $782-787$.

van den Berg, B., Wong, A., van der Velden, P., Boshuizen, H., Grievink, L., 2012. Disaster exposure as a risk factor for mental health problems, eighteen months, four and ten years post-disaster - a longitudinal study. BMC Psychiatry 12 (1), 147.

Breslau, N., Kessler, R.C., Chilcoat, H.D., Schultz, L.R., Davis, G.C., Andreski, P., 1998. Trauma and posttraumatic stress disorder in the community: the 1996 Detroit area survey of trauma. Arch. Gen. Psychiatry 55, 626-632.

Brunet, J., McDonough, M.H., Hadd, V., Crocker, P.R.E., Sabiston, C.M., 2010. The Posttraumatic Growth Inventory: an examination of the factor structure and invariance among breast cancer survivors. Psycho-Oncol. 19 (8), 830-838.

Cann, A., Calhoun, L.G., Tedeschi, R.G., Taku, K., Vishnevsky, T., Triplett, K.N., Danhauer, S.C., 2010. A short form of the Posttraumatic Growth Inventory. Anxiety, Stress, Coping 23 (2), 127-137.

Dyer, G., Gilroy, N., Bradford, J., Brice, L., Kabir, M., Greenwood, M., Larsen, S.R., Moore, J., Hertzberg, M., Kwan, J., 2016a. A survey of fertility and sexual health following allogeneic haematopoietic stem cell transplantation in New South Wales, Australia. Br. J. Haematol. 172 (4), 592-601.

Dyer, G., Gilroy, N., Brown, L., Hogg, M., Brice, L., Kabir, M., Greenwood, M., Larsen, S.R., Moore, J., Hertzberg, M., 2016b. What they want: inclusion of blood and marrow transplantation survivor preference in the development of models of care for long-term health in Sydney, Australia. Biol. Blood Marrow Transplant. 22 (4), $731-743$.

Helgeson, V.S., Reynolds, K.A., Tomich, P.L., 2006. A meta-analytic review of benefit finding and growth. J. Consult. Clin. Psychol. 74 (5), 797-816.

Hooper, L.M., Marotta, S.A., Depuy, V., 2009. A confirmatory factor analytic study of the Posttraumatic Growth Inventory among a sample of racially diverse college students. J. Ment. Health 18 (4), 335-343.

Hoyle, R., 2012. Handbook of Structural Equation Modeling. Guildford Press, New York, NY.

Hu, L., Bentler, P.M., 1999. Cutoff criteria for fit indexes in covariance structure analysis: conventional criteria versus new alternatives. Struct. Equ. Model. 6 (1), 1-55.

Jaarsma, T.A., Pool, G., Sanderman, R., Ranchor, A.V., 2006. Psychometric properties of the Dutch version of the posttraumatic growth inventory among cancer patients. Psycho-Oncology 15 (10), 911-920.

Jayawickreme, E., Blackie, L.E.R., 2014. Post-traumatic growth as positive personality change: evidence, controversies and future directions. Eur. J. Personal. 28 (4), 312-331.

Joseph, S., Linley, A.P., 2004. Positive change following trauma and adversity: a review. J. Trauma. Stress 17 (1), 11-21.

Kaler, M.E., Erbes, C.R., Tedeschi, R.G., Arbisi, P.A., Polusny, M.A., 2011. Factor structure and concurrent validity of the Posttraumatic Growth Inventory-Short Form among veterans from the Iraq war. J. Trauma. Stress 24 (2), 200-207.

Kenny, D.A., McCoach, D.B., 2003. Effect of the number of variables on measures of fit in structural equation modeling. Struct. Equ. Model. 10, 333-351.

Lamela, D., Figueiredo, B., Bastos, A., Martins, H., 2014. Psychometric properties of the Portuguese version of the Posttraumatic Growth Inventory Short Form among divorced adults. Eur. J. Psychol. Assess. 30 (1), 3-14.

Linley, P.A., Andrews, L., Joseph, S., 2007. Confirmatory factor analysis of the posttraumatic growth inventory. J. Loss Trauma 12 (4), 321-332.

Mack, J., Herrberg, M., Hetzel, A., Wallesch, C.W., Bengel, J., Schulz, M., Rohde, N., Schönberger, M., 2015. The factorial and discriminant validity of the German version of the Post-traumatic Growth Inventory in stroke patients. Neuropsychol. Rehabil. 25 (2), 216-232.

Maercker, A., Langner, R., 2001. Posttraumatic personal growth: validation of German versions of two questionnaires. Diagnostica 47 (3), 153-162.

Maguen, S., Vogt, D.S., King, L.A., King, D.W., Litz, B.T., 2006. Posttraumatic growth among Gulf War I veterans: the predictive role of deployment-related experiences and background characteristics. J. Loss Trauma 11 (5), 373-388.

Merkle, Ec, You, D., Preacher, K.J., 2015. Testing nonnested structural equation models Psychol. Methods Adv. Online Publ..

Morris, A., Shakespeare-Finch, J., Scott, J.L., 2012. Posttraumatic growth after cancer: the importance of health-related benefits and newfound compassion for others. Support. Care Cancer 20, 749-756.

Morris, B.A., Wilson, B., Chambers, S.K., 2013. Newfound compassion after prostate cancer: a psychometric evaluation of additional items in the Posttraumatic Growth Inventory. Support. Care Cancer 21 (12), 3371-3378.

O’Rourke, N., Hatcher, L., 2013. A Step-by-Step Approach to Using SAS ${ }^{\circledR}$ for Factor Analysis and Structural Equation Modeling 2nd ed.. SAS Institute Inc, Cary, NC.

O’Toole, B.I., Catts, S.V., Outram, S., Pierse, K.R., Cockburn, J., 2009. The physical and 
mental health of Australian Vietnam veterans 3 decades after the war and its relation to military service, combat, and Post-Traumatic Stress Disorder. Am. J. Epidemiol. 170 (3), 318-330.

Palmer, G.A., Graca, J.J., Occhietti, K.E., 2012. Confirmatory factor analysis of the Posttraumatic Growth Inventory in a veteran sample with Posttraumatic Stress Disorder. J. Loss Trauma 17 (6), 545-556.

Picoraro, J.A., Womer, J.W., Kazak, A.E., Feudtner, C., 2014. Posttraumatic growth in parents and pediatric patients. J. Palliat. Med. 17 (2), 209-218.

Prati, G., Pietrantoni, L., 2014. Italian adaptation and confirmatory factor analysis of the full and the short form of the Posttraumatic Growth Inventory. J. Loss Trauma 19 (1), 12-22.

Rajandram, R.K., Jenewein, J., McGrath, C., Zwahlen, R.A., 2011. Coping processes relevant to posttraumatic growth: an evidence-based review. Support. Care Cancer 19 (5), 583-589.

Sears, S.R., Stanton, A.L., Danoff-Burg, S., 2003. The yellow brick road and the emerald city: benefit finding, positive reappraisal coping, and posttraumatic growth in women with early-stage breast cancer. Health Psychol. 22, 487-497.

Sheikh, A.I., Marotta, S.A., 2005. A cross-validation study of the posttraumatic growth inventory. Meas. Eval. Couns. Dev. 38 (2), 66-77.

Sledjeski, E.M., Speisman, B., Dierker, L.C., 2008. Does number of lifetime traumas explain the relationship between PTSD and chronic medical conditions? Answers from the National Comorbidity Survey-Replication (NCS-R). J. Behav. Med. 31 (4), $341-349$.

Solomon, Z., Dekel, R., 2007. Posttraumatic stress disorder and posttraumatic growth among Israeli ex-POWs. J. Trauma. Stress 20 (3), 303-312.
Splevins, K., Cohen, K., Bowley, J., Joseph, S., 2010. Theories of posttraumatic growth: cross-cultural perspectives. J. Loss Trauma 15 (3), 259-277.

Steel, Z., Silove, D., Phan, T., Bauman, A., 2002. Long-term effect of psychological trauma on the mental health of Vietnamese refugees resettled in Australia: a population-based study. Lancet 360 (9339), 1056-1062.

Taku, K., Oshio, A., 2015. An item-level analysis of the Posttraumatic Growth Inventory: relationships with an examination of core beliefs and deliberate rumination. Personal. Individ. Differ. 86, 156-160.

Taku, K., Calhoun, G.B., Tedeschi, R.G., Gil-Rivas, V., Kilmer, R.P., Cann, A., 2007. Examining posttraumatic growth among Japanese university students. Anxiety Stress Coping 20, 353-367.

Taku, K., Cann, A., Calhoun, L.G., Tedeschi, R.G., 2008. The factor structure of the posttraumatic growth inventory: a comparison of five models using confirmatory factor analysis. J. Trauma. Stress 21 (2), 158-164.

Taubman-Ben-Ari, O., Findler, L., Sharon, N., 2011. Personal growth in mothers: examination of the suitability of the Posttraumatic Growth Inventory as a measurement tool. Women Health 51 (6), 604-622.

Tedeschi, R.G., Calhoun, L.G., 1996. The Posttraumatic Growth Inventory: measuring the positive legacy of trauma. J. Trauma. Stress 9 (3), 455-471.

Tedeschi, R.G., Calhoun, L.G., 2004. Posttraumatic growth: conceptual foundations and empirical evidence. Psychol. Inq. 15, 1-18.

Teixeira, R.J., Pereira, M.G., 2013. Growth and the cancer caregiving experience: psychometric properties of the Portuguese Posttraumatic Growth Inventory. Fam. Syst. Health 31 (4), 382-395. 